\section{Cigarette smoking and glaucoma in the United States population}

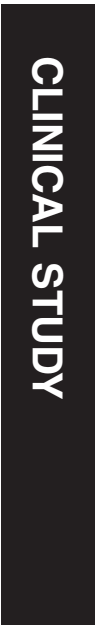

${ }^{1}$ Department of Ophthalmology, Stein Eye Institute, David Geffen School of Medicine, University of California Los Angeles, Los Angeles, CA, USA

${ }^{2}$ Department of Biostatistics, Fielding School of Public Health, University of California Los Angeles, Los Angeles, CA, USA

Correspondence:

AL Coleman, Jules Stein Eye Institute, UCLA, David Geffen School of Medicine at UCLA, 100 Stein Plaza, Stein Eye Institute, Los Angeles, CA 90095, USA. Tel: +1 310825 5298, Fax: +1 310206 7773, E-mail: coleman@jsei.ucla. edu

Received: 13 May 2017 Accepted in revised form: 28 October 2017

Published online: 5 January 2018

\author{
Abstract \\ Purpose To evaluate the association between \\ cigarette smoking and glaucoma in the \\ United States population. \\ Patients and methods US civilian, non- \\ institutionalized population from 2005 to 2008 \\ administrations of the National Health and \\ Nutrition Examination Survey that were $\geq 40$ \\ years of age with visual fields and optic disc \\ photographs were included. Diagnosis of \\ glaucoma was based on the Rotterdam \\ criteria. Logistic regression modeling was \\ performed to assess the association between \\ glaucoma and smoking history, while \\ controlling for age, gender, ethnicity, \\ household income, alcohol consumption, \\ diabetes, and hypertension. \\ Results In 3864 participants, 212 (5.5\%) had \\ glaucoma (corresponds to a population \\ weighted glaucoma prevalence of $3.7 \%$ in a \\ total of 83570127 subjects). Population \\ weighted proportion of current smokers was \\ $\mathbf{2 0 . 6} \%$ and ex-smokers was $\mathbf{2 8 . 3} \%$. Participants \\ with glaucoma were older $(63.0 \pm 11.6$ vs \\ $56.1 \pm 11.2, P=0.002)$, likely to be male $(57.1 \%$ \\ vs $49.2 \%, P=0.03)$, to be Black $(36.3 \%$ vs \\ $20.7 \%, P<0.001)$, and to have diabetes $(18.9 \%$ \\ vs $12.4 \%, P=0.006)$ and hypertension $(50.5 \%$ \\ vs $39.7 \%, P=0.003)$. Current smokers had a \\ lower odds of glaucoma compared to non-

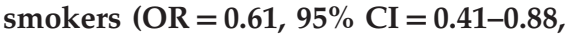 \\ $P=0.009)$, and ex-smokers $(\mathrm{OR}=0.46,95 \%$ \\ $\mathrm{CI}=0.28-0.76, P=0.002)$. The effect estimates \\ were similar in adjusted models, but not \\ statistically significant. Among smokers, \\ greater pack/day of smoking history was \\ associated with statistically significantly \\ higher odds of glaucoma $(\mathrm{OR}=1.70,95 \%$ \\ $\mathrm{CI}=1.08-2.67, P=0.02)$. \\ Conclusions Among cigarette smokers, \\ heavy smoking defined by greater number of \\ pack of cigarettes smoked per day is \\ associated with higher odds of glaucoma. \\ Health care providers should include this
}

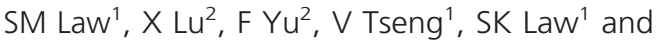
AL Coleman ${ }^{1}$ association when counseling patients on their smoking habit.

Eye (2018) 32, 716-725; doi:10.1038/eye.2017.292; published online 5 January 2018

\section{Introduction}

Smoking has been shown to be an important risk factor in the development of eye diseases such as cataract, age-related macular degeneration (AMD), Graves' ophthalmopathy, diabetic retinopathy, and dry-eye syndrome. ${ }^{1-6}$ Because of the strong associations between smoking and AMD, the latest 2014 United States (U.S.) Surgeon General report calls on all eye healthcare providers to assess and address the smoking status of their patients. ${ }^{7}$ However, even though there is compelling evidence that smoking is associated with some common sightthreatening diseases, the relationship between smoking and glaucoma remains unclear. ${ }^{8}$

A high likelihood of glaucoma has been reported in smokers with heavy and long duration of cigarette consumption, according to some case-controlled studies. ${ }^{9-12}$ However, in population-based surveys, no consistent association between smoking and glaucoma has been found. ${ }^{13-19}$ Some studies have even reported that smoking is associated with a reduced risk of glaucoma. ${ }^{15,20}$

Although a positive relationship between glaucoma and cigarette smoking is disputed by some researchers, extensive evidence of various detrimental physiological effects of cigarette smoking on our body exists in the literature. ${ }^{7}$ Many active compounds found in tobacco smoke are toxic to ocular tissues, affecting the eye through ischemic or oxidative mechanisms. ${ }^{21}$

Glaucoma is one of the leading causes of global blindness with the number of people affected projected to increase to 111.8 million in $2040 .^{22}$ There are $\sim 1$ billion smokers in the 
world, or about $13.5 \%$ of the world's population. ${ }^{23}$ Even if smoking is only associated with a small increase of odds of glaucoma development or in a subtype of glaucoma patients, an alteration of cigarette-smoking behavior may have a significant impact globally.

To better study the relationship between cigarette smoking and glaucoma, a large and representative sample or population is required. The National Health and Nutrition Examination Survey (NHANES) is an annual survey conducted by the National Center for Health Statistics (NCHS), the Centers for Disease Control and Prevention (CDC). The survey measures health and nutritional status in the general U.S. civilian, noninstitutionalized population. The survey draws from a broad and diverse population in the U.S. and is unique in combining interviews, physical examinations, and laboratory tests. The purpose of this study is to evaluate the association between smoking and glaucoma in participants of the U.S. NHANES.

\section{Subjects and methods}

This study is a retrospective, cross-sectional study based on the 2005-2006 and 2007-2008 U.S. NHANES

databases. These two cycles of the survey were chosen in particular, because the examinations included perimetric testing and optic disc photographs, which can be used to assess the diagnosis of glaucoma. Data accumulation was performed by the NCHS with approval from the NCHS Research Ethics Review Board. ${ }^{24}$ Data from NHANES are publicly available without participant's identifiable data included, so this study received exemption from the Institutional Review Board of the University of California, Los Angeles, USA.

In the 2005-2006 and 2007-2008 data cycles, perimetric testing (N30-5 algorithm of frequency doubling technology (FDT) perimetry, Carl Zeiss Meditec, Inc, Dublin, California, USA) and optic disc photographs were performed on eligible participants. The N-30-5 FDT screening protocol was administered to survey participants. It is a 19-point supra-threshold screening test that was administered prior to the Retinal Imaging Exam. Exclusion criteria were participants with a documented non-glaucomatous explanation for abnormal cup-to-disc ratio (CDR) on optic disc photos (dysplastic disc, marked anisometropia), and participants with a documented nonglaucomatous explanation for abnormal visual fields (retinal vascular disease, macular degeneration, cerebrovascular disease).

The primary outcome variable was the presence or absence of glaucoma diagnosis. The algorithms to interpret the visual fields and optic disc photographs have been reported in a prior publication. ${ }^{25}$ Two visual field tests per eye were administered to each participant, and an eye was considered to have a glaucomatous visual field defect (GVFD) if at least 2 locations in both the first and second tests were below the $1 \%$ threshold level, and at least 1 failed location was the same on both tests (2-2-1 algorithm). Full details of the method of visual field testing and interpretation are publically available at the NHANES website. ${ }^{26}$ The vertical CDR and asymmetry was used to identify glaucomatous loss of the neuroretinal rim according to International Society for Geographical and Epidemiological Ophthalmology (ISGEO) criteria. ${ }^{27}$ A CDR value or CDR asymmetry value outside the 97.5th percentile of normal population was considered to be possible glaucomatous optic neuropathy (GON), while value outside the 99.5th percentile was considered to be probable GON. The GVFD status was matched with GON status to reach the classification of definite, probably, possible, or no glaucoma based on the Rotterdam Eye Study criteria. ${ }^{25,28}$ Rotterdam Eye Study criteria was used in order for the results of this study to be comparable with other studies on NHANES database. For analytical purposes of this study, participants with both structural and functional evidence of glaucoma, that is, definite glaucoma defined by presence of GVFD and either possible or probable GON, were considered to have glaucoma.

The primary predictor variable was smoking status. Exposure variable data regarding smoking included number of years smoked, number of cigarettes smoked daily or when quit, age when started smoking and quitting, age last smoked cigarettes regularly, and serum cotinine level.

Potential confounding variables were collected from the NHANES database including age, gender, race/ethnicity, alcohol consumption, body mass index (BMI, as continuous variable), education level, annual household income, self-reported diabetes mellitus and hypertension, history of steroid use, and refractive error. ${ }^{29,30}$ The spherical equivalent of each eye was calculated and categorized as emmetropia ( -0.99 to +0.99 diopters (D)), myopia $(\leq-1.00 \mathrm{D})$, and hyperopia $(\geq+1.00 \mathrm{D})$.

Hyperlipidemia and cardiovascular diseases such as cerebral vascular accident or myocardial infarction were not included because of the exploratory purpose of our study. The role of lipid levels on glaucoma risk is still unclear. A recent risk factors analysis based on the NHANES 2005-2008 data showed that different cholesterol levels (total cholesterol, high-density lipoprotein, low-density lipoprotein) were not associated with glaucoma, but triglyceride levels $\geq 200 \mathrm{mg} / \mathrm{dl}$ were inversely associated with glaucoma. ${ }^{31}$ The authors acknowledged that this effect may be related to use of systemic medications in people with metabolic disturbances. $^{31,32}$ The cardiovascular diseases collected in the NHANES are self-reported and have strong clinical 
association with underlining diagnoses of diabetes mellitus and hypertension, which were already included as potential confounding variables. Use of systemic phosphodiesterase inhibitors (sildenafil and theophylline) was found to be associated with greater prevalence of self-reported glaucoma based on the NHANES 2005-2008 data. ${ }^{33}$ However, in our sample with both visual field and optic disc available for diagnosis for glaucoma, the number of participants reportedly using these two agents (three subjects were using sildenafil and seven subjects were using theophylline) was too small for including these two agents for analysis.

\section{Statistical analysis}

All statistical analysis followed the NHANES analytic guidelines, which incorporate the complex multistage probability survey design, and sampling weights of NHANES data. ${ }^{34}$ The NHANES is a weighted survey such that each participant carries different sampling weight, which represents the US population.

Consequently, all computed estimates are truly representative of the U.S. civilian non-institutionalized population. The sampling weight of each participant was provided by in NHANES to calculate the overall US population 40 years or older, glaucoma prevalence, and proportion of smokers. ${ }^{35}$ Descriptive statistics were used to describe the glaucoma status, smoking exposure and baseline characteristics for the study population. These descriptive statistics were calculated and reported based on unweighted estimates in the study sample and NHANES population-weighted estimates. Smoking exposure history was divided into groups of ex-smokers (those who had quit smoking), current smoker (those who were smoking at time of survey), and non-smokers (those who have never smoked). The amount of smoking exposure in ex-smokers and current smokers combined was sorted into quartiles based on total number of cigarettes smoked: 100-1800 cigarettes (equivalent to 0.34.9 pack-years), 1801-6000 cigarettes (4.9-16.4 packyears), 6001-12 000 cigarettes (16.4-32.9 pack-years), and more than 12000 cigarettes (>32.9 pack-years). The packyear is a unit to quantify the amount of cigarette smoking and is calculated by multiplying the number of packs of cigarettes smoked per day by the number of years the person has smoked. Multiplication of number of packyear by 365.24 days per year and 20 cigarettes per pack provides us with the number of cigarettes smoked. Despite the unit being called a pack-year and is widely used in patient care, the actual unit is simply a total number of packs or cigarettes smoked. Thus, the amount of smoking exposure was analyzed based on the number of packs of cigarettes smoked per day. The effects of duration of smoking, and in the subset of ex-smokers, the interval of quitting of smoking were also analyzed.

Cotinine is the primary metabolite of nicotine from tobacco with a serum half-life of $16 \mathrm{~h}$ and can be used as an objective marker of exposure to cigarette smoke including secondhand smoke (SHS). Although serum cotinine level has limitations in differentiating ex-smokers from non-smokers or representing the amount, duration, and type of tobacco exposure, it can, at least, provide an objective way to identify current smokers. Thus, we separately analyzed the relationship of cotinine level and glaucoma by dividing the participants into four groups based on a screening scheme of smokers proposed by Benowitz et al, Jarvis et al, and recommended by the Society for Research on Nicotine and Tobacco biochemical assessment working group: (1) $\geq 14 \mathrm{ng} / \mathrm{ml}$ (active smokers), (2) $0.5-13.9 \mathrm{ng} / \mathrm{ml}$ (recent smokers or significantly exposed to SHS), (3) $0.05-0.49 \mathrm{ng} / \mathrm{ml}$ (lightly exposed to SHS), and (4) $<0.05 \mathrm{ng} / \mathrm{ml}$ (unexposed). ${ }^{36-38}$ Cigarette smokers and nonsmokers were distinguished by the cotinine cutoff of $3 \mathrm{mg} / \mathrm{ml}$ based on a representative US population sample (NHANES data from 1999 to 2004)..$^{39}$

Logistic regression modeling was performed to assess the association between smoking history and glaucoma. Unadjusted models were created for history of smoking, amount and duration of smoking, and cotinine level as predictors of glaucoma. Variables with a $P$-value of less than 0.25 (age, gender, ethnicity, household income, alcohol consumption, diagnosis of diabetes and hypertension) were included in an adjusted model as potential confounders for association between smoking and glaucoma. Variables that were not included in the adjusted models were BMI, educational level, history of steroid use, and refractive errors (all $P \geq 0.25$ except for history of steroid use). The number of participants with history of steroid use (6 participants) was too low to have any significant effect. Refractive errors of the right eye categorized into emmetropia, myopia and hyperopia were not associated with glaucoma. Analysis was repeated for the left eye and there was no substantial difference from those found for the right eye, so only the results of the right eye are reported here. All analyses were conducted with SAS version 9.3 (SAS Institute, Inc., Cary, North Carolina, USA). Statistical significance was defined by $P$-value of $<0.05$.

\section{Results}

There were 83570127 participants in the weighted 20052006 and 2007-2008 NHANES samples and 3864 actual participants that met the inclusion criteria. The overall prevalence of glaucoma was 3.7\% $(n=3076410)$ in the 
Table 1 Characteristics of actual participants in 2005-2006 and 2007-2008 NHANES

\begin{tabular}{|c|c|c|c|c|}
\hline & All subjects & Non-Glaucoma subjects & Glaucoma subjects & P-value \\
\hline Total number of subjects & 3864 & 3652 & 212 & \\
\hline Mean age (year $\pm S D)$ & $56.4 \pm 11.3$ & $56.1 \pm 11.2$ & $63.0 \pm 11.6$ & 0.002 \\
\hline Male gender & 1917 & $1796(49.2 \%)$ & $121(57.1 \%)$ & 0.03 \\
\hline Ethnicity: & & & & $<0.001$ \\
\hline White & 1949 & $1879(51.5 \%)$ & $70(33.0 \%)$ & \\
\hline Black & 831 & $754(20.7 \%)$ & $77(36.3 \%)$ & \\
\hline Hispanic & 934 & $884(24.2 \%)$ & $50(23.6 \%)$ & \\
\hline Others & 150 & $135(3.7 \%)$ & $15(7.1 \%)$ & \\
\hline Educational level: & & & & 0.50 \\
\hline Less than ninth grade & 491 & $457(12.5 \%)$ & $34(16.0 \%)$ & \\
\hline Ninth grade to less than high school graduate & 570 & $537(14.7 \%)$ & $33(15.6 \%)$ & \\
\hline High school graduate or general educational development equivalent & 951 & $897(24.6 \%)$ & $54(25.5 \%)$ & \\
\hline Some college & 1005 & $954(26.1 \%)$ & $51(24.1 \%)$ & \\
\hline College graduate and beyond & 846 & $806(22.1 \%)$ & $40(18.9 \%)$ & \\
\hline Annual household income (\$): & & & & 0.06 \\
\hline$<20000$ & 682 & $645(21.7 \%)$ & $37(22.0 \%)$ & \\
\hline $20000-44999$ & 1124 & $1049(35.2 \%)$ & $75(44.6 \%)$ & \\
\hline $45000-74999$ & 778 & $746(25.1 \%)$ & $32(19.1 \%)$ & \\
\hline$\geq 75000$ & 458 & $441(14.8 \%)$ & $17(10.1 \%)$ & \\
\hline$\geq 20000$ & 103 & $96(3.2 \%)$ & $7(4.2 \%)$ & \\
\hline Diabetes Mellitus (self-reported) & 492 & $452(12.4 \%)$ & $40(18.9 \%)$ & 0.006 \\
\hline Hypertension (self-reported) & 1555 & $1449(39.7 \%)$ & $106(50.5 \%)$ & 0.003 \\
\hline Steroid use (self-reported) & 6 & $5(0.2 \%)$ & $1(0.9 \%)$ & 0.23 \\
\hline Body mass index $\left(\mathrm{kg} / \mathrm{m}^{2} \pm \mathrm{SD}\right)$ & $29.2 \pm 6.6$ & $29.3 \pm 6.6$ & $28.6 \pm 5.5$ & 0.97 \\
\hline Alcohol consumption (number of drinks / day \pm SD) & $1.7 \pm 2.5$ & $1.8 \pm 2.5$ & $1.4 \pm 1.8$ & 0.24 \\
\hline Refractive error (diopters (D), right eye) & & & & 0.50 \\
\hline Myopia $(\leq-1.00 \mathrm{D})$ & 882 & $838(22.9 \%)$ & $44(20.8 \%)$ & \\
\hline Emmetropia (-0.99 to $0.99 \mathrm{D})$ & 2076 & $1964(53.8 \%)$ & $112(52.8 \%)$ & \\
\hline Hyperopia $(\geq+1.00 \mathrm{D})$ & 901 & $845(23.1 \%)$ & $56(26.4 \%)$ & \\
\hline Non-smoker & 1897 & $1801(49.3 \%)$ & $96(45.3 \%)$ & 0.25 \\
\hline Smoker (current and Ex-smoker): & 1967 & $1851(50.7 \%)$ & $116(54.7 \%)$ & \\
\hline Current smoker & 814 & $779(42.1 \%)$ & $35(30.2 \%)$ & 0.01 \\
\hline Ex-Smoker & 1153 & $1072(57.9 \%)$ & $81(69.8 \%)$ & \\
\hline Cotinine $(\mathrm{ng} / \mathrm{ml} \pm \mathrm{SD})$ & $62.6 \pm 134.3$ & $63.2 \pm 134.8$ & $51.6 \pm 124.4$ & 0.91 \\
\hline Cup/Disc-ratio ( \pm SD, right eye) & $0.41 \pm 0.12$ & $0.40 \pm 0.11$ & $0.59 \pm 0.14$ & $<0.001$ \\
\hline Cup/Disc-ratio ( \pm SD, left eye $)$ & $0.41 \pm 0.12$ & $0.40 \pm 0.11$ & $0.60 \pm 0.14$ & $<0.001$ \\
\hline
\end{tabular}

Bold values are statistically significant $\mathrm{P}$-values (i.e. $\mathrm{P}<0.05$ ).

weighted sample and 5.5\% $(n=212)$ in the actual sample. The overall population-weighted proportion of current smokers and ex-smokers was $20.6 \%$ and $28.3 \%$, respectively. For those participants excluded from the analysis, the population-weighted proportion of current smokers and ex-smokers was $19.5 \%$ and $33.5 \%$, respectively.

Table 1 summarizes the characteristics of the nonglaucoma and glaucoma participants in the actual sample. The mean age (years $\pm S D$ ) of the glaucoma participants was greater than that of the non-glaucoma participants $(63.0 \pm 11.6$ and $56.1 \pm 11.2$, respectively, $P=0.002)$. The glaucoma group had a higher proportion of males than the non-glaucoma group (57.1\% vs $49.2 \%$, respectively, $P=0.03)$, higher percentage of Black participants $(36.3 \%$ vs $20.7 \%$, respectively, $P<0.001$ ), and higher rate of diagnosis of diabetes mellitus (18.9\% vs $12.4 \%$, respectively, $P=0.006)$ and hypertension (50.5\% vs, $39.7 \%$, respectively, $P=0.003$ ).

There were no statistically significant differences in the proportion of smokers or non-smokers between the group of glaucoma participants and the group of non-glaucomatous participants. However, the proportion of ex-smokers was significantly higher in the group of participants with glaucoma compared to those without glaucoma ( $69.8 \%$ vs $57.9 \%$, respectively, $P=0.01)$, and the proportion of current smokers was significantly higher in the group without glaucoma compared to the glaucoma group ( $42.1 \%$ vs $30.2 \%$, respectively, $P=0.01$; Table 1 ).

Table 2 summarizes the relationships between smoking and glaucoma. In the unadjusted analysis, compared to non-smokers, ex-smokers had a higher odds of glaucoma (OR $=1.31,95 \% \mathrm{CI}=0.91-1.88, P=0.15$, statistically nonsignificant), but current smokers had a lower odds of 
Table 2 Odds ratios for the presence of glaucoma among smokers vs non-smokers of the actual participants in 2005-2006 and 20072008 NHANES

\begin{tabular}{|c|c|c|c|c|}
\hline & $\begin{array}{c}\text { Unadjusted } \\
\text { Odd Ratio (95\% CI) }\end{array}$ & $\begin{array}{l}\text { Unadjusted } \\
\text { P-value }\end{array}$ & $\begin{array}{c}\text { Adjusted }^{\mathrm{a}} \\
\text { Odd Ratio }(95 \% \text { CI) }\end{array}$ & $\begin{array}{c}\text { Adjusted }^{\mathrm{a}} \\
\text { P-value }\end{array}$ \\
\hline \multicolumn{5}{|l|}{ Smoking History } \\
\hline Ex-smokers vs Non-smokers & $1.31(0.91-1.88)$ & 0.15 & $1.15(0.69-1.92)$ & 0.59 \\
\hline Current smokers vs Non-smokers & $0.61(0.41-0.88)$ & 0.009 & $0.68(0.41-1.12)$ & 0.13 \\
\hline Current smokers vs Ex-smokers & $0.46(0.28-0.76)$ & 0.002 & $0.59(0.29-1.20)$ & 0.14 \\
\hline \multicolumn{5}{|l|}{ Among smokers (Ex-smokers and Current smokers): } \\
\hline Smoking duration (per year) & $1.02(0.99-1.05)$ & 0.16 & $1.00(0.97-1.02)$ & 0.82 \\
\hline Smoking amount (per pack/day) & $1.31(0.98-1.75)$ & 0.07 & $1.70(1.08-2.67)$ & 0.02 \\
\hline \multicolumn{5}{|l|}{ Pack-years of smoking } \\
\hline First quartile (0.3-4.9 pack-years) & 1 (Reference) & & 1 (Reference) & \\
\hline Second quartile ( $>$ 4.9-16.4 pack-years) & $0.89(0.39-2.04)$ & 0.79 & $0.59(0.23-1.55)$ & 0.29 \\
\hline Third quartile ( $>$ 16.4-32.9 pack-years) & $0.88(0.41-1.89)$ & 0.74 & $0.74(0.27-2.04)$ & 0.56 \\
\hline Fourth quartile ( > 32.9 pack-years) & $1.50(0.66-3.42)$ & 0.34 & $1.41(0.44-4.54)$ & 0.56 \\
\hline Cotinine level $(>3 \mathrm{ng} / \mathrm{ml})$ & $1.00(1.00-1.00)$ & 0.35 & $1.00(1.00-1.00)$ & 0.70 \\
\hline \multicolumn{5}{|l|}{ Among ex-smokers } \\
\hline Interval since quitting smoking (per year) & $1.02(1.00-1.05)$ & 0.05 & $0.99(0.96-1.04)$ & 0.91 \\
\hline
\end{tabular}

${ }^{a}$ Adjusted for age, gender, ethnicity, household income, alcohol consumption, diagnosis of diabetes and hypertension. Bold values are statistically significant $\mathrm{P}$-values (i.e. $\mathrm{P}<0.05$ ).

Table 3 Odds Ratios for the different cotinine levels and the presence of glaucoma of the actual participants in 2005-2006 and 20072008 NHANES

\begin{tabular}{|c|c|c|c|c|}
\hline & $\begin{array}{c}\text { Unadjusted } \\
\text { Odd Ratio }(95 \% \text { CI) }\end{array}$ & $\begin{array}{l}\text { Unadjusted } \\
\text { P-value }\end{array}$ & $\begin{array}{c}\text { Adjusted }^{\mathrm{a}} \\
\text { Odd Ratio }(95 \% \mathrm{CI})\end{array}$ & $\begin{array}{c}\text { Adjusted }^{\mathrm{a}} \\
\text { P-value }\end{array}$ \\
\hline \multicolumn{5}{|l|}{ Cotinine level } \\
\hline$<0.05 \mathrm{ng} / \mathrm{ml}$ (unexposed) & 1 (Reference) & & 1 (Reference) & \\
\hline $0.05-0.49 \mathrm{ng} / \mathrm{ml}$ (lightly exposed to secondhand smoke) & $1.02(0.59-1.76)$ & 0.96 & $0.89(0.46-1.70)$ & 0.72 \\
\hline $\begin{array}{l}0.5-13.9 \mathrm{ng} / \mathrm{ml} \text { (recent smokers or significantly exposed to } \\
\text { secondhand smoke) }\end{array}$ & $1.04(0.58-1.87)$ & 0.90 & $1.11(0.56-2.22)$ & 0.76 \\
\hline$\geq 14 \mathrm{ng} / \mathrm{ml}$ (active smokers) & $0.69(0.49-0.97)$ & 0.03 & $0.88(0.56-1.39)$ & 0.59 \\
\hline
\end{tabular}

${ }^{a}$ Adjusted for age, gender, ethnicity, household income, alcohol consumption, diagnosis of diabetes and hypertension. Bold values are statistically significant P-values (i.e. $\mathrm{P}<0.05)$.

glaucoma $(\mathrm{OR}=0.61,95 \% \mathrm{CI}=0.41-0.88, P=0.009)$. Compared to ex-smokers, current smokers had a lower odds of glaucoma $(\mathrm{OR}=0.46,95 \% \mathrm{CI}=0.28-0.76$, $P=0.002)$. Among smokers (ex-smokers and current smokers), compared to the first quartile of the amount of smoking, defined by the total number of cigarettes smoked or pack-years of smoking, heavy smoking (fourth quartile ( $>32.9$ pack-years)) had the highest odds of glaucoma $(\mathrm{OR}=1.50,95 \% \mathrm{CI}=0.66-3.42, P=0.34$, statistically non-significant), while there were no apparent differences in the odds of glaucoma in other subgroups (second quartile: $\mathrm{OR}=0.89,95 \% \mathrm{CI}=0.39-2.04, P=0.79$; third quartile: $\mathrm{OR}=0.88,95 \% \mathrm{CI}=0.41-1.89, P=0.74$ ). Active smoking defined by cotinine level of $\geq 14 \mathrm{ng} / \mathrm{ml}$ was associated with lower odds of glaucoma compared to those who were not exposed to cigarette smoke defined by cotinine level of $<0.05 \mathrm{ng} / \mathrm{ml}(\mathrm{OR}=0.69,95 \%$ $\mathrm{CI}=0.49-0.97, P=0.03$, unadjusted analysis; Table 3)

Although pack-years of smoking is typically used to quantify the cumulative amount of smoking, the duration of smoking is not well-represented. Therefore, we separately evaluated the relationship between the duration of smoking and the number of packs of cigarettes smoked per day with glaucoma. Among smokers, the duration (year) of smoking was not associated with glaucoma $(\mathrm{OR}=1.02,95 \% \mathrm{CI}=0.99-1.05$, $P=0.16)$, but there was a trend of association between the number of cigarettes smoked per day and glaucoma in the unadjusted model (OR $=1.31,95 \% \mathrm{CI}=0.98-1.75$, $P=0.07$, unadjusted analysis; Table 2).

Since ex-smokers have higher odds of glaucoma compared to current smokers, we evaluated whether the 
risk of glaucoma changes over time in ex-smokers. Among ex-smokers, each year of quitting smoking was associated with a $2 \%$ increase in the odds of having glaucoma $(\mathrm{OR}=1.02,95 \% \mathrm{CI}=1.00-1.05, P=0.05$, unadjusted analysis; Table 2).

Adjusted models were created by including variables that had $P$-values $<0.25$ (age, gender, ethnicity, household income, alcohol consumption, diagnosis of diabetes, and hypertension) as potential confounders in the relationship between smoking and glaucoma. In the adjusted models, the results were not statistically significant, except that the association in smokers between each pack of cigarettes per day increase and glaucoma became stronger $(\mathrm{OR}=1.70,95 \% \mathrm{CI}=1.08-2.67, P=0.02$; Tables 2 and 3) As myopia is considered a possible risk factor for glaucoma according to some studies, ${ }^{40}$ we reanalyzed the data by adding myopia as a confounding factor in the adjusted model and found that the significance of the results remained unchanged. In particular, in the adjusted model with myopia included as one of the confounding factors, the association in smokers between each pack of cigarettes per day increase and glaucoma remained statistically significant $(\mathrm{OR}=1.52$, 95\% CI $=1.01-1.28, P=0.04)$.

\section{Discussion}

In this cross-sectional study based on the 2005-2006 and 2007-2008 NHANES databases, a nationally

representative health examination survey on U.S. civilian, non-institutionalized population, we found a statistically significant association between cigarette smoking and glaucoma. Most of the association between smoking and glaucoma lose significance in adjusted analysis suggesting that the associations are due to confounding. However, among smokers, greater pack per day of smoking history was associated with higher odds of glaucoma after adjusted for confounders.

The relationship between smoking and glaucoma has been conflicting and not, as well delineated as that between smoking and other ocular diseases such as cataract and AMD. 2,3,8 Although a few studies have shown a positive association between smoking and glaucoma, no association was found in population-based studies. In a case-control study using an exploratory health questionnaire comparing 83 patients with definite primary open angle glaucoma (POAG), 121 POAG suspects, and 237 controls, current cigarette smoking was found to be positively associated with glaucoma $\left(\mathrm{OR}=2.9 ;\right.$ 95\% CI 1.3-6.6). ${ }^{9}$ Fan and associates reported an almost 11-fold increase in the odds of POAG in 32 Chinese cigarette smoking adults compared to 96 age and sex-matched controls. ${ }^{10}$ In a prospective study following a large cohort of Black Women's Health Study participants from 1995 to 2007, Wise and co-authors reported that POAG was associated with both long-duration and highintensity current smoking. ${ }^{11}$ However, when smoking as a life-style variable was examined in population-based studies, including the Beaver Dam Eye Study, Rotterdam Study, Proyecto Visual and Eye Research, Los Angeles Latino Eye Study, Behavioral Risk Factor Surveillance System, Nurses' Health Study (NHS), Health Professionals Follow-up Study (HPFS), and the Thessaloniki Eye Study, no association was found between smoking and glaucoma. ${ }^{13-19}$

The discrepancies among studies on the association between smoking and glaucoma may be partly due to the complexity of the relationship. In the univariate analysis of our study, it was found that current smokers seemed to have reduced odds and ex-smokers higher odds of glaucoma compared to non-smokers. Such an opposite association between different histories of smoking habit and glaucoma may have led to inconsistent or conflicting results in population-based surveys. A similar finding was reported by Ko and associates analyzing a number of risks factors for glaucoma also based on the NHANES data from 2005 to 2008. ${ }^{31}$ In this analysis, participants with glaucoma were less likely to be current smokers than non-smokers $(9.0 \%$ vs $20.7 \%$, respectively, $P=0.002)$.

However, it is unclear if ex-smokers were included in the non-smokers category or simply excluded from the analysis. ${ }^{31}$ In our study, active smoking defined by cotinine level was also associated with lower odds of glaucoma compared to those without exposure to cigarette smoke $(\mathrm{OR}=0.69,95 \% \mathrm{CI}=0.49-0.97, P=0.03)$. Although in Ko's study and our study, associations found in the univariate analysis were not statistically significant when adjusted for other variables, the possibility of lower odds of glaucoma in current smokers as compared to nonsmokers or ex-smokers is intriguing and has been reported in the literature. ${ }^{15,20,41} \mathrm{~A}$ modest inverse relationship has been observed in a study based on the NHS and HPFS data that greater pack-years of smoking was associated with lower odds of glaucoma (relative risk (RR) $0.78,95 \% \mathrm{CI}=0.55-1.11$ ) compared to those who had never smoked. ${ }^{15}$ A follow-up study showed that smokers with greater pack-years of cigarette smoking had a significantly lower risk of glaucoma with paracentral visual field defect compared with glaucoma with peripheral visual field defect (per 10 pack-years; hazard ratio $(\mathrm{HR})=0.92(95 \% \mathrm{CI}=0.87-0.98)$ vs $\mathrm{HR}=0.98(95 \%$ $\mathrm{CI}=0.94-1.01)$, respectively). ${ }^{33}$ Studies on the effects of low doses of nicotine on different subtypes of glaucoma or glaucoma at different stages may further elucidate the effects of nicotine and cigarette smoking.

Smoking may have multiple detrimental effects on the eye. Various mechanisms that can compromise the ocular circulation have been proposed, including 
vasoconstriction of the episcleral veins, ${ }^{34}$ compromised arterial blood flow to the optic nerve head, ${ }^{42,43}$ alterations in ocular blood flow, ${ }^{43-45, " ~ a n d ~ i n c r e a s i n g ~ b l o o d ~ v i s c o s i t y ~}$ and inducing vasospasms. ${ }^{20,46,47}$ Smoking also enhances the generation of free radicals and decreases the levels of antioxidants in the blood circulation, aqueous humor, and ocular tissue. ${ }^{48}$ Increased oxidant stress was shown in the anterior segment, for example, trabecular meshwork as well as in the posterior pole of glaucoma patients. ${ }^{49}$ Inflammation and apoptotic marker levels in aqueous humor and plasma were found to be increased in smokers as well. ${ }^{50}$

Despite the adverse effects of smoking or nicotine on ocular circulation and tissues, protective mechanisms of nicotine on the optic nerve circulation have been proposed. Nicotine may induce the liberation of nitric oxide from perivascular nitrergic neurons, resulting in vasodilatation. ${ }^{19,51,52}$ In a case-control study based on the data of the NHS and the HPFS, association between cigarette smoking and glaucoma was found to be dependent on nitric oxide synthase 3 (NOS3) gene variations. ${ }^{53}$ Variations in NOS3 single-nucleotide polymorphisms would affect levels of nitric oxide derived from vascular endothelium. However, different nitric oxide levels can result in opposite effects. While high levels of nitric oxide can induce beneficial vasodilation that leads to increased optic nerve blood flow, nitric oxide can also induce hyperperfusion damage and reactions that form peroxynitrites, free radicals that induce retinal ganglionic cell death. ${ }^{53}$ Thus, it is possible that cigarette smoking or nicotine may have both adverse and protective effects on the optic nerve.

Other nicotinic neuroprotective effects for glaucoma have been proposed. In an in vivo glaucoma model by injecting sodium chloride into the episcleral veins of adult Long Evans rat eyes, prior intravitreal injection of an alpha-7 nicotinic acetylcholine receptor agonist, PNU-282987, was found to have a neuroprotective effect against loss of retinal ganglion cells. ${ }^{54}$ Eye drops of PNU-282987 given topically were detectable in the retina and were found to have similar neuroprotection in a dosedependent manner. ${ }^{55}$ However, the glaucoma model used in these studies may not be analogous to how glaucoma develops in human and the route of nicotine absorption from smoking is apparently different from those used in these experiments.

A loss of a possible neuroprotective effect of nicotine may be the reason behind the increased likelihood of glaucoma amongst ex-smokers in our study. A similar increased risk amongst ex-smokers as compared to current smokers is also observed in Parkinsonism: a chronic, neurodegenerative disease. ${ }^{56-58}$ However, it may also be due to a lower tendency to develop a smoking habit or a greater ease of quitting smoking as in
Parkinsonism. ${ }^{59}$ Changes in life-style and behavior are quite common in patients with a chronic and potentially debilitating disease. It is possible that glaucoma patients are more likely to quit smoking after being diagnosed with glaucoma or more motivated to quit smoking from other medical problems directly or indirectly related to smoking, such as pulmonary and cardiovascular diseases that may have some contribution to the development and progression of glaucoma. It is important to emphasize that age factor cannot be ignored, since a smoker ages as each year interval since quitting smoking, and the result of higher odds of glaucoma amongst ex-smokers was statistically non-significant in adjust analysis.

The current study suggested that heavy smokers (fourth quartile) have a higher risk of glaucoma compared to mild or moderate smoking. Similar results were noted in a case-controlled study by age-matching 339 patients with glaucoma and 339 patients with ocular hypertension. ${ }^{12}$ Glaucoma was found to be associated with higher frequency of heavy smoking (40 pack-years or more, $\mathrm{OR}=3.93)$, but not with moderate (20-40 packyears) and mild smoking ( $<20$ pack-year). ${ }^{12}$ The cutoff for defining heavy smoking is similar to our study (32.9 pack-years or 12000 cigarettes). This suggests that the protective effects of smoking, if there are any, may be eliminated in heavy smoking. In addition, the dependence and addictive potential of nicotine or smoking is wellproven, and that any recommendation of using smoking as a mean of neuroprotection is irresponsible and dangerous. ${ }^{7}$

Our study has several limitations primarily related to its cross-sectional design. Since the time of glaucoma onset was unknown, the status of smoking might not be ascertained at the time of glaucoma onset. For instance, a glaucoma subject who currently smokes might have started smoking after glaucoma onset, that is, a nonsmoker at the onset of glaucoma; whilst a glaucoma subject who is an ex-smoker might have been a current smoker at the onset of glaucoma, that is, the subject quit smoking after a glaucoma diagnosis. Moreover, even though statistical methods were used to adjust for confounding variables, their influence may not be completely controlled. Because several of the variables, such as smoking, diagnosis of hypertension, and diagnosis of diabetes are self-reported, there are measurement error and recall bias. Although serum cotinine level provides an objective measure for verifying current smoking status, it cannot be used to differentiate ex-smokers from non-smokers, and the level changes over time after smoking. ${ }^{38}$ The analysis of this study did not include intraocular pressure as it was not collected in the NHANES. Intraocular pressure data might further refine the classification of some participants in addition to ISGEO criteria. By using both structural and functional 
criteria to diagnose glaucoma, we believe our study has identified participants with glaucoma more accurately than studies that relied solely on self-reporting criteria. Despite more stringent criteria, a large representative population-based sample could still be included in our analysis. Since the glaucoma status could not be assessed in those participants that were not included in our study, their relationships between the smoking status and glaucoma could not be analyzed, though we believe that they should not be different from our study sample. Another limitation is that information on electronic cigarette usage, nicotine replacement therapies (NRT) and other non-cigarette smoking products (for example. cigars, water pipes, bidis, kreteks, and cheroot) was not obtained in detail. Further studies examining the effects of NRT upon glaucoma are warranted due to their widespread use and elimination of the numerous toxic ingredients from cigarette smoke. ${ }^{60}$

\section{Summary}

What was known before

- Even though there is compelling evidence that smoking is associated with some common sight-threatening diseases such as cataract and age-related macular degeneration, the relationship between smoking and glaucoma remains unclear.

- Glaucoma is one of the leading causes of global blindness and there are approximately 1 billion smokers in the world, or about $13.5 \%$ of the world's population.

- Even if smoking is only associated with a small increase of odds of glaucoma development or in a subtype of glaucoma patients, an alteration of cigarette-smoking behavior may have a significant impact globally.

\section{What this study adds}

- Multiple factors of smoking on ocular health and our body and the complexity of the relationship between smoking and glaucoma may be the reason of discrepancies among studies on their association.

- Among smoker, heavy smoking defined by greater pack/ day of history of cigarette smoking is shown to have a statistically significant association with higher likelihood of a diagnosis of glaucoma.

- Eye-health care providers should consider this association when counseling patients on their smoking habit.

\section{Conflict of interest}

The authors declare no conflict of interest.

\section{Acknowledgements}

Supported by an unrestricted grant from Research to Prevent Blindness, Inc., New York, New York, to the Stein Eye Institute. Center for Community Outreach and Policy
Sponsors or funding organizations had no role in the design or conduct of this research.

\section{References}

1 Moss SE, Klein R, Klein BE. Prevalence of and risk factors for dry eye syndrome. Arch Ophthalmol. 2000; 118(9): 1264-1268.

2 Thornton J, Edwards R, Mitchell P, Harrison RA, Buchan I, Kelly SP. Smoking and age-related macular degeneration: a review of association. Eye 2005; 19(9): 935-944.

3 Kelly SP, Thornton J, Edwards R, Sahu A, Harrison R. Smoking and cataract: review of causal association. J Cataract Refract Surg. 2005; 31(12): 2395-2404.

4 Thornton J, Kelly SP, Harrison RA, Edwards R. Cigarette smoking and thyroid eye disease: a systematic review. Eye 2007; 21(9): 1135-1145.

5 Coleman AL, Seitzman RL, Cummings SR, Yu F, Cauley JA, Ensrud KE et al. The association of smoking and alcohol use with age-related macular degeneration in the oldest old: the study of osteoporotic fractures. Am J Ophthalmol. 2010; 149 (1): 160-169.

6 Asfar T, Lam BL, Lee DJ. Smoking causes blindness: time for eye care professionals to join the fight against tobacco. Invest Ophthalmol Vis Sci. 2015; 56(2): 1120-1121.

7 U.S. Department of Health and Human Services. The Health Consequences of Smoking: 50 Years of Progress. A Report of the Surgeon General. Atlanta, GA USA: Department of Health and Human Prevention and Health Promotion, Office on Smoking and Health. Printed with corrections, 2014.

8 Edwards R, Thornton J, Ajit R, Harrison RA, Kelly SP. Cigarette smoking and primary open angle glaucoma: a systematic review. J Glaucoma. 2008; 17(7): 558-566.

9 Wilson MR, Hertzmark E, Walker AM, Childs-Shaw K, Epstein DL. A case-control study of risk factors in open angle glaucoma. Arch Ophthalmol. 1987; 105(8): 1066-1071.

10 Fan BJ, Leung YF, Wang N, Lam SC, Liu Y, Tam OS et al. Genetic and environmental risk factors for primary openangle glaucoma. Chin Med J. 2004; 117(5): 706-710.

11 Wise LA, Rosenberg L, Radin RG, Mattox C, Yang EB, Palmer JR et al. A prospective study of diabetes, lifestyle factors, and glaucoma among African-American women. Ann Epidemiol. 2011; 21(6): 430-439.

12 Renard JP, Rouland JF, Bron A, Sellem E, Nordmann JP, Baudouin $\mathrm{C}$ et al. Nutritional, lifestyle and environmental factors in ocular hypertension and primary open-angle glaucoma: an exploratory case-control study. Acta Ophthalmol. 2013; 91(6): 505-513.

13 Klein BE, Klein R, Ritter LL. Relationship of drinking alcohol and smoking to prevalence of open-angle glaucoma. The Beaver Dam Eye Study. Ophthalmology 1993; 100(11): 1609-1613.

14 Quigley HA, West SK, Rodriguez J, Munoz B, Klein R, Snyder R. The prevalence of glaucoma in a population-based study of Hispanic subjects: Proyecto VER. Arch Ophthalmol. 2001; 119(12): 1819-1826.

15 Kang JH, Pasquale LR, Rosner BA, Willett WC, Eqan KM, Faberowski $\mathrm{N}$ et al. Prospective study of cigarette smoking and the risk of primary open-angle glaucoma. Arch Ophthalmol. 2003; 121(12): 1762-1768.

16 Doshi V, Ying-Lai M, Azen SP, Varma RLos Angeles Latino Eye Study Group. Sociodemographic, family history, and 
lifestyle risk factors for open-angle glaucoma and ocular hypertension. The Los Angeles Latino Eye Study. Ophthalmology 2008; 115(4): 639-647.

17 Zhang X, Kahende J, Fan AZ, Barker L, Thompson TJ, Mokdad $\mathrm{AH}$ et al. Smoking and visual impairment among older adults with age-related eye diseases. Prev Chronic Dis. 2011; 8(4): A84.

18 Ramdas WD, Wolfs RC, Hofman Ade Jong PT, Vingerling JR, Jansonius NM. Lifestyle and risk of developing openangle glaucoma: the Rotterdam study. Arch Ophthalmol. 2011; 129(6): 767-772.

19 Topouzis F, Wilson MR, Harris A, Founti P, Yu F, Anastasopoulos $\mathrm{E}$ et al. Risk factors for primary open-angle glaucoma and pseudoexfoliative glaucoma in the Thessaloniki eye study. Am J Ophthalmol. 2011; 152(2): 219-228.

20 Buys YM, Harasymowycz P, Gaspo R, Kwok K, Hutnik CM, Blondeau $\mathrm{P}$ et al. Comparison of newly diagnosed ocular hypertension and open-angle glaucoma: ocular variables, risk factors, and disease severity. J Ophthalmol 20122012; 757106.

21 Solberg Y, Rosner M, Belkin M. The association between cigarette smoking and ocular diseases. Surv Ophthalmol. 1998; 42(6): 535-547.

22 Tham YC, Li X, Wong TY, Quigley HA, Aung T, Cheng CY. Global prevalence of glaucoma and projections of glaucoma burden through 2040: a systematic review and metaanalysis. Ophthalmology 2014; 121(11): 2081-2090.

23 World Health Organization. Smoking Fact Sheets. Available at http://www.who.int/mediacentre/factsheets/fs339/en/ . Accessed 29.06. 2016.

24 Centers for Disease Control and Prevention. NCHS Ethics Review Board (ERB) Approval. Available at http://www. cdc.gov/nchs/nhanes/irba98.htm. Accessed 29.06.2016.

25 Shaikh Y, Yu F, Coleman AL. Burden of undetected and untreated glaucoma in the United States. Am J Ophthalmol. 2014; 158(6): 1121-1129.

26 Centers for Disease Control and Prevention. NHANES 20052006, Data documentation, codebook, and frequencies, ophthalmology-frequency doubling technology (OPXFDT_D). Available at https://wwwn.cdc.gov/Nchs/ Nhanes/2005-2006/FFQDC_D.htm. Accessed 29.06.2016.

27 Foster PJ, Buhrmann R, Quigley HA, Johnson GJ. The definition and classification of glaucoma in prevalence surveys. Br J Ophthalmol. 2002; 86(2): 238-242.

28 Wolfs RC, Borger PH, Ramrattan RS, Klaver CC, Hulsman CA, Hofman A et al. Changing views on open-angle glaucoma: definitions and prevalences-the rotterdam study. Invest Ophthalmol Vis Sci. 2000; 41(11): 3309-3321.

29 Centers for Disease Control and Prevention. NHANES 20052006. Available at http://wwwn.cdc.gov/Nchs/Nhanes/ Search/nhanes05_06.aspx. Accessed 29.06.2016.

30 Centers for Disease Control and Prevention. NHANES 20072008. Available at http://wwwn.cdc.gov/Nchs/Nhanes/ Search/nhanes07_08.aspx. Accessed 29.06.2016.

31 Ko F, Boland MV, Gupta P, Gadkaree SK, Vitale S, Gualler E et al. Diabetes, triglyceride levels, and other risk factors for glaucoma in the National Health and Nutrition Examination Survey 2005-2008. Invest Ophthalmol Vis Sci. 2016; 57(4): 2152-2157.

32 Talwar N, Musch DC, Stein JD. Association of daily dosage and type of statin agent with risk of open-angle glaucoma. JAMA Ophthamol. 2017; 135(3): 263-267.
33 Chen SP, Singh K, Lin SC. Use of phosphodiesterase inhibitors and prevalence of self-reported glaucoma in the United States. PLoS ONE 2017; 12(8): e0183388.

34 Centers for Disease Control and Prevention. NHANES III Web Tutorial: Sample Design. Available at https://www. cdc.gov/nchs/tutorials/NHANES/SurveyDesign/ SampleDesign/intro_iii.htm. Accessed 29.06.2016.

35 Centers for Disease Control and Prevention. Specifying Weighting Parameters. Available at https://www.cdc.gov/ nchs/tutorials/NHANES/SurveyDesign/Weighting/intro_ iii.htm. Accessed 29.06.2016.

36 Benowitz NL, Jacob P III, Ahijevych K et al. Biochemical verification of tobacco use and cessation. Nicotine Tob Res. 2002; 4(2): 149-159.

37 Jarvis MJ, Tunstall-Pedoe H, Feyerabend C et al. Comparison of tests used to distinguish smokers from nonsmokers. Am J Public Health. 1987; 77(11): 1435-1438.

38 Benowitz NL, Schultz KE, Haller CA, Wu AH, Dains KM, Jacob P 3rd. Prevalence of smoking assessed biochemically in an urban public hospital: a rationale for routine cotinine screening. Am J Epidemiol. 2009; 170(7): 885-891.

39 Benowitz NL, Bernert JT, Caraballo RS et al. Optimal serum cotinine levels for distinguishing cigarette smokers and nonsmokers within different racial/ethnic groups in the United States between 1999 and 2004. Am J Epidemiol. 2009; 169(2): 236-248.

40 Qiu M, Wang SY, Singh K, Lin SC. Association between myopia and glaucoma in the United States population. Invest Ophthalmol Vis Sci. 2013; 54(1): 830-835.

41 Kang JH, Loomis SJ, Rosner BA, Wiggs JL, Pasquale LR. Comparison of risk factor profiles for primary open-angle glaucoma subtypes defined by pattern of visual field loss: a prospective study. Invest Ophthalmol Vis Sci. 2015; 56(4): 2439-2448.

42 Mehra KS, Roy PN, Khare BB. Tobacco smoking and glaucoma. Ann Ophthalmol. 1976; 8(4): 462-464.

43 Kaiser HJ, Schoetzau A, Flammer J. Blood flow velocity in the extraocular vessels in chronic smokers. $\mathrm{Br} \mathrm{J} \mathrm{Ophthalmol.}$ 1997; 81(2): 133-135.

44 Williamson TH, Lowe GD, Baxter GM. Influence of age, systemic blood pressure, smoking, and blood viscosity on orbital blood velocities. Br J Ophthalmol. 1995; 79(1): 17-22.

45 Hara K. Effects of cigarette smoking on ocular circulation chronic effect on choroidal circulation. Nippon Ganka Gakkai Zasshi. 1991; 95(10): 939-943.

46 Klaver JH, Greve EL, Goslinga H, Geijssen HC, Heuvelmans $\mathrm{JH}$. Blood and plasma viscosity measurements in patients with glaucoma. Br J Ophthalmol. 1985; 69(10): 765-770.

47 Rojanapongpun P, Drance SM. The effects of nicotine on the blood flow of the ophthalmic artery and the finger circulation. Graefes Arch Clin Exp Ophthalmol. 1993; 231(7): 371-374.

48 Cheng AC, Pang CP, Leung AT, Chua JK, Fan DS, Lam DS. The association between cigarette smoking and ocular diseases. Hong Kong Med J. 2000; 6(2): 195-202.

49 Erb C, Heinke M. Oxidative stress in primary open-angle glaucoma. Frontiers in Bioscience (Elite Edition). 2011;3: 1524-1533.

50 Zanon-Moreno V, Garcia-Medina JJ, Zanon-Viguer V, Moreno-Nadal MA, Pinazo-Duran MD. Smoking, an additional risk factor in elder women with primary openangle glaucoma. Mol Vis. 2009; 15: 2953-2959. 
51 Toda N, Nakanishi-Toda M. Nitric oxide: ocular blood flow, glaucoma, and diabetic retinopathy. Prog Retin Eye Res. 2007; 26(3): 205-238.

52 Toda N, Kitamura Y, Okamura T. Role of nitroxidergic nerve in dog retinal arterioles in vivo and arteries in vitro. Am J Physiol. 1994; 266(5 Pt 2): H1985-H1992.

53 Kang JH, Wiggs JL, Rosner BA, Haines J, Abdrabou W, Pasquale LR. Endothelial nitric oxide synthase gene variants and primary open-angle glaucoma: interactions with hypertension, alcohol intake, and cigarette smoking. Arch Ophthalmol. 2011; 129(6): 773-780.

54 Iwamoto K, Birkholz P, Schipper A, Mata D, Linn DM, Linn CL. A nicotinic acetylcholine receptor agonist prevents loss of retinal ganglion cells in a glaucoma model. Invest Ophthalmol Vis Sci. 2014; 55(2): 1078-1087.

55 Mata D, Linn DM, Linn CL. Retinal ganglion cell neuroprotection induced by activation of alpha7 nicotinic acetylcholine receptors. Neuropharmacology. 2015; 99: 337-346.
56 Moccia M, Erro R, Picillo M, Vassallo E, Vitale C, Longo K et al. Quitting smoking: an early non-motor feature of Parkinson's disease? Parkinsonism Relat Disord. 2015; 21(3): 216-220.

57 Li X, Li W, Liu G, Shen X, Tang Y. Association between cigarette smoking and Parkinson's disease: a meta-analysis. Arch Gerontol Geriatr. 2015; 61(3): 510-516.

58 Ritz B, Ascherio A, Checkoway H, Marder KS, Nelson LM, Rocca WA et al. Pooled analysis of tobacco use and risk of Parkinson disease. Arch Neurol. 2007; 64(7): 990-997.

59 Ritz B, Lee PC, Lassen CF, Arah OA. Parkinson disease and smoking revisited: ease of quitting is an early sign of the disease. Neurology. 2014; 83(16): 1396-1402.

60 Kasza KA, Ambrose BK, Conway KP, Borek N, Taylor K, Goniewicz ML et al. Tobacco-product use by adults and youths in the United States in 2013 and 2014. N Eng J Med. 2017; 376: 342-353. 